\section{Pulmonary benign metastasising leiomyoma: response to treatment with goserelin}

\author{
T Z Jacobson, E J Rainey, \\ C W G Turton
}

\begin{abstract}
Benign metastasising leiomyoma is a rare disease occuring predominantly in women of childbearing age and is hormonally influenced. The response of the disease to the luteinising hormone releasing hormone analogue goserelin is reported.

(Thorax 1995;50:1225-1226)
\end{abstract}

Keywords: metastasising leiomyoma, goserelin.

Benign metastasising leiomyoma is a rare disease which is part of a spectrum that also includes lymphangioleiomyomatosis. The two disorders are histologically distinct but both are hormonally influenced and remission has been reported following menopause or surgical castration. ${ }^{1}$ Pulmonary manifestations are most common and reported treatment methods have included progesterone, antioestrogens, oophorectomy, ${ }^{2}$ lung transplantation, ${ }^{3}$ and medical castration using luteinising hormone releasing hormone (LHRH) analogues. ${ }^{45} \mathrm{Re}$ ported results of all methods are variable in outcome. ${ }^{67}$ In this paper we present a patient with benign metastasising leiomyoma who has shown radiographic, physiological and symptomatic improvement with the use of the LHRH analogue goserelin.

\section{Case report}

A 41 year old white smoker and mother of six children presented in June 1989 with the development of a large haematoma following a biopsy under local anaesthetic for what subsequently proved to be a benign breast lump. Evacuation of the haematoma under general anaesthetic was required. Preoperatively she was noted to be cyanosed and had inspiratory and expiratory wheeze. Intraoperatively a persistent low arterial saturation was noted whilst breathing room air, and the patient was transferred to the intensive care unit for ventilation overnight. A chest radiograph (fig 1) revealed large nodular shadows throughout both lung fields. The past medical history revealed that she had undergone total hysterectomy in 1981 when histological examination of the uterus showed a single fibroid $6 \mathrm{~cm}$ in diameter. In 1986 she complained of dizziness and nausea which was

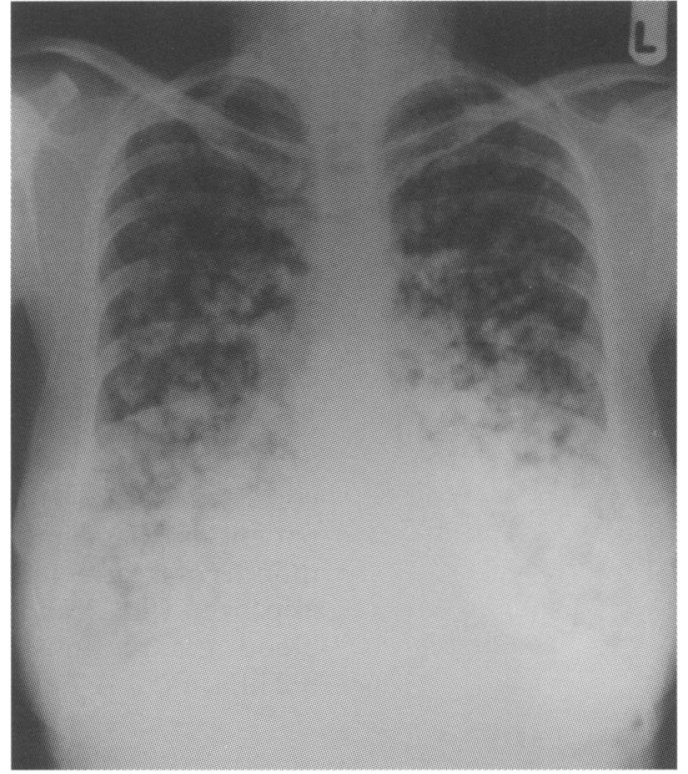

Figure 1 Chest radiograph at presentation showing multiple nodular opacities of varying size throughout the lungs.

diagnosed as benign positional vertigo. She was noted then to be a heavy smoker who on examination was obese and peripherally cyanosed.

In June 1989 routine tests including full blood count, urea and electrolytes, liver function tests, blood and sputum cultures and cytology, tumour markers, antibody and serology screens were all normal. An abdominal ultrasound scan was unremarkable, a thyroid ultrasound scan revealed three nodules in the left lobe, and biopsy specimens showed a nodular goitre.

Bronchoscopic washings for acid fast bacilli and cytological examination were negative. Histological examination of transbronchial biopsy samples showed typical features of benign metastasising leiomyoma with well circumscribed nodules of spindled mature smooth muscle cells arranged in swirling bundles. There was no mitotic activity or cellular pleomorphism and no lymphatic involvement.

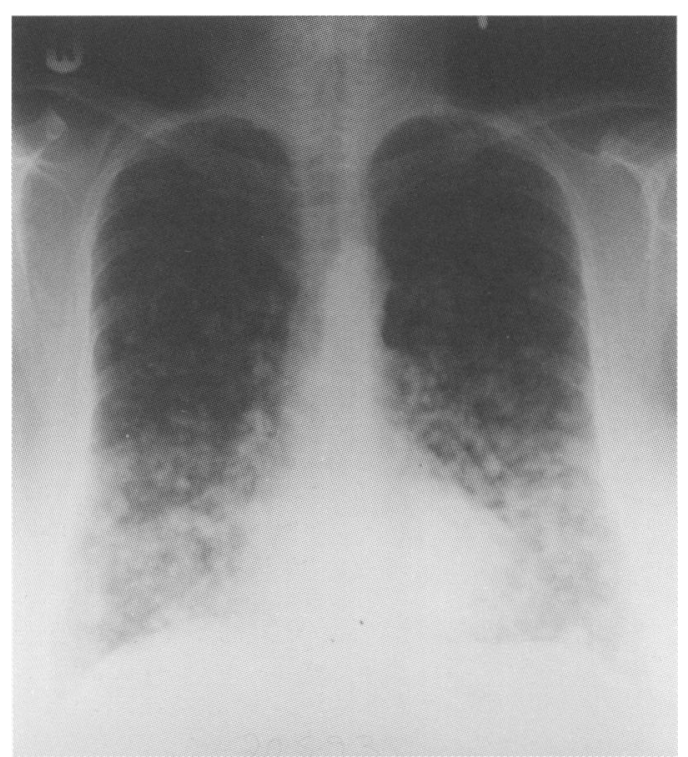

Figure 2 Chest radiograph after two years of treatment with goserelin. 
The patient was initially given the progesterone analogue, medroxyprogesterone acetate, and oxygen for 16 hours daily. A month later tamoxifen was added. Progesterone was stopped in December 1989 due to side effects of ear, jaw, and throat pains. The disease showed no response to this treatment regimen which was discontinued in March 1990. The LHRH analogue goserelin was then given in a dose of $3.6 \mathrm{mg}$ subcutaneously monthly. Before treatment arterial blood gas tensions were $\mathrm{Po}_{2}$ $6.7 \mathrm{kPa}, \mathrm{PCO}_{2} 5.4 \mathrm{kPa}, \mathrm{pH} 7.41$ breathing air. Since that time there has been a slow but consistent improvement. Symptomatically the patient is managing well at home after 42 months of treatment. The chest radiograph has improved (fig 2) and in October 1993 arterial blood gas tensions breathing air were $\mathrm{Po}_{2}$ $8 \cdot 2 \mathrm{kPa}, \mathrm{PCO}_{2} 4 \cdot 7 \mathrm{kPa}, \mathrm{pH} 7 \cdot 43$.

\section{Discussion}

Benign metastasising leiomyoma is a rare disease usually restricted to women of childbearing age with previous uterine fibroids. Histological examination shows smooth muscle tumours at a distant site, usually the lungs, which appear benign in that there are few mitotic figures, no nuclear pleomorphism, and no invasion. There are similarities of clinical expression, hormonal dependence, and histological appearance with lymphangioleiomyomatosis. However, lymphangioleiomyomatosis is more rapidly progressive, it may be complicated by pneumothoraces, and radiographically it shows an interstitial pattern of infiltration rather than a macronodular appearance. Histologically, the tumour nodules in benign metastasising leiomyoma are larger, and spare lymphatic vessels, blood vessels, airways, and air spaces and are not associated with emphysematous changes.
Cases with intermediate features have been described. ${ }^{1}$

In our case treatment with the LHRH analogue goserelin was followed by regression, though failure of similar treatment has been reported. ${ }^{6}$ The patient's menopausal status was not documented endocrinologically before treatment and she had had a hysterectomy. However, there were no systemic menopausal symptoms before treatment, while flushes and sweats were very troublesome soon after commencing goserelin. It seems much more likely that improvement was due to treatment than a spontaneous menopause.

The contradiction inherent in the term "benign metastasising leiomyoma" is unsatisfactory. Perhaps it reflects our poor understanding of the pathophysiology of the disease and its rarity. Multicentre treatment trials are not practicable, but a central register of cases would help further research and advance understanding.

1 Banner AS, Carrington CB, Emory WB, Kittle F, Leonard G, Ringus J. Efficacy of oophorectomy in lymphangioleiomyomatosis and benign metastasising leiomyoma $N$ Engl F Med 1981;305:204-9.

2 Adamson D, Heinrichs WL, Raybin DM, Raffin TA. Successful treatment of pulmonary lymphangioleiomyomatosis with oophorectomy and progesterone. Am Rev Respir Dis 1985;132:916-21.

3 Sleiman C, Herve M, Jebrak G, Darne C, Meeus E, Dubois F. Pulmonary lymphangioleiomyomatosis treated by single lung transplantation. Am Rev Respir Dis 1992;145: 964-6.

4 Maheux R, Parent JG, Samson Y, Jean C, Farid N. Utilisation of luteinizing hormone-releasing hormone agonist in pulof luteinizing hormone-releasing hormone agonist in

5 Hague WM, Abdulwahid NA, Jacobs HS, Craft I. Use of Hague WM, Abdulwahid NA, Jacobs HS, Craft I. Use of
LHRH analogue to obtain reversible castration in a patient with benign metastasising leiomyoma. $\mathrm{Br} \mathcal{F}$ Obstet Gynaecol 1986;93:455-60.

6 Radermecker M, Broux R, Corhay JL, Limet R, Radermecker $M$. Failure of buserelin-induced medical castration to control lymphangioleiomyomatosis in two patients. Chest 1992 101:1724-6.

7 Eliasson AH, Phillips YY, Tenholder MF. Treatment of lymphangioleiomyomatosis: a meta-analysis. Chest 1989; 196:1352-5. 